\title{
Economic burden of attention-deficit/ hyperactivity disorder among adults in the United States: a societal perspective
}

\author{
Jeff Schein, DrPH, MPH; Lenard A Adler, MD; Ann Childress, MD; Patrick Gagnon-Sanschagrin, MSc; \\ Mikhaïl Davidson, BA; Frédéric Kinkead, MA; Martin Cloutier, MSc; Annie Guérin, MSc; and Patrick Lefebvre, MA
}

\section{What is already known about this subject}

- An estimated $35 \%-78 \%$ of individuals diagnosed with attention-deficit/ hyperactivity disorder (ADHD) during childhood maintain symptoms and meet some criteria for ADHD through adulthood.

- ADHD is associated with substantial clinical burden as individuals transition to adulthood, including higher rates of comorbidities, mortality, incarceration, and psychiatric hospitalizations than in individuals without ADHD.

- The literature on the economic burden of ADHD in the United States is scarce and has focused on specific populations, has been limited to specific cost components (eg, direct health care costs), or has used data that may be somewhat outdated.

\section{What this study adds}

- An estimated $8,716,972$ adults live with ADHD in the United States, resulting in a total societal excess cost attributable to ADHD of $\$ 122.8$ billion ( $\$ 14,092$ per adult).

- Excess costs of unemployment ( $\$ 66.8$ billion; 54.4\%) comprised the largest proportion of the total, followed by productivity loss ( $\$ 28.8$ billion; $23.4 \%$ ) and health care services (\$14.3 billion; 11.6\%).

- These results suggest that ADHD in adults, and its associated costs, which are already important to patients and family members, must also be recognized by providers and payers.

\section{ABSTRACT}

BACKGROUND: Attention-deficit/hyperactivity disorder (ADHD) is associated with substantial clinical burden as individuals transition to adulthood, including higher rates of comorbidities, mortality, incarceration, and psychiatric hospitalizations than in individuals without ADHD. These higher rates likely contribute to substantial economic burden as well.

OBJECTIVE: To provide a comprehensive evaluation of the economic burden associated with ADHD in the US adult population.

METHODS: Direct health care costs were obtained by using claims data from the IBM MarketScan Research Databases (January 1, 2017, through December 31, 2018). Direct non-health care costs and indirect costs were estimated on the basis of the literature and government publications. Excess costs incurred by adults with ADHD during 2018 were evaluated from a societal perspective; per-patient costs were extrapolated to the national level.

\begin{abstract}
Author affiliations
Jeff Schein, DrPH, MPH, Otsuka

Pharmaceutical Development \& Commercialization, Inc., Princeton, NJ. Lenard A Adler, MD, New York University Grossman School of Medicine, New York, NY. Ann Childress, MD, Center for Psychiatry and Behavioral Medicine, Las Vegas, NV. Patrick Gagnon-Sanschagrin, MSc; Mikhaïl Davidson, BA; Frédéric Kinkead, MA; Martin Cloutier, MSc; Annie Guérin, MSc; and Patrick Lefebvre, MA, Analysis Group, Inc., Montréal, Québec, Canada.

AUTHOR CORRESPONDENCE :

Patrick Gagnon-Sanschagrin, 514.394.4472;

Patrick.Gagnon-Sanschagrin@analysisgroup.com
\end{abstract}

J Manag Care Spec Pharm. 2022;28(2):168-79

Copyright $\odot 2022$, Academy of Managed Care Pharmacy. All rights reserved.

RESULTS: An estimated 8.7 million adults live with ADHD in the United States, resulting in a total societal excess cost attributable to ADHD of $\$ 122.8$ billion ( $\$ 14,092$ per adult). Excess costs of unemployment ( $\$ 66.8$ billion; $54.4 \%$ ) comprised the largest proportion of the total, followed by productivity loss ( $\$ 28.8$ billion; $23.4 \%$ ) and health care services (\$14.3 billion; $11.6 \%)$.

CONCLUSIONS: ADHD in adults is associated with substantial economic burden. 
Attention-deficit/hyperactivity disorder (ADHD) is a neurodevelopmental condition characterized by persistent symptoms of inattention or hyperactivity-impulsivity that impair daily function. ${ }^{1,2}$ Although it is more prevalent among children, an estimated $4.4 \%$ of adults live with ADHD in the United States. ${ }^{3}$ The clinical course of ADHD is highly heterogeneous, and the associated functional impairment persists through adulthood in a substantial proportion of patients. Approximately 35\%-78\% of individuals diagnosed with ADHD during childhood maintain symptoms and meet some criteria for ADHD through adulthood., ${ }^{4,5}$

Individuals with ADHD have difficulty coping with increasing self-care and role obligations as they transition to adulthood, ${ }^{6,7}$ which can lead to several deleterious outcomes if the ADHD is left untreated. For instance, ADHD is associated with higher rates of road traffic accidents, ${ }^{8,9}$ incarceration, ${ }^{7}$ and psychiatric hospitalizations ${ }^{7}$ than among individuals without ADHD. Certain psychiatric comorbidities, including substance use disorder (SUD), ${ }^{6,710}$ anxiety disorders, bipolar disorder, ${ }^{3}$ and major depressive disorder ${ }_{1}^{11}$ are also particularly common among individuals with ADHD. ADHD is also associated with increased unemployment and reduced work productivity. ${ }^{6}$ In addition, individuals with ADHD have a significantly higher risk of mortality than individuals without ADHD, independent of psychiatric comorbidities. ${ }^{7,12}$

These detrimental outcomes suggest that the economic burden of ADHD in adults is substantial. Nonetheless, most prior studies conducted in the United States focused on specific populations (eg, commercially insured patients) who may not be representative of the general US population, were limited to specific cost components (eg, direct health care costs) that may not fully capture the societal burden of ADHD, or used data that may be somewhat outdated. ${ }^{13-22}$ For instance, a systematic literature review by Doshi et al ${ }^{14}$ estimated annual incremental costs of \$105\$194 billion for adults with ADHD, based on studies from 1990 to 2011. Accordingly, the present study was conducted in order to provide an updated and comprehensive evaluation of the total direct health care, direct non-health care, and indirect costs associated with ADHD among the US adult population.

\section{Methods}

\section{DATA SOURCES}

Direct health care costs for adult patients with ADHD (aged 18-64 years) were obtained by using health insurance claims data from the IBM MarketScan Research Databases for the period covering January 1, 2017, through December 31, 2018.
A comprehensive review of the literature, including nationally representative government surveys, was conducted in order to identify and assess other cost components relevant to ADHD in adults (aged 18-64 years), including direct nonhealth care costs and indirect costs.

In the calculation of direct health care costs, data were deidentified and comply with the patient requirements of the Health Insurance Portability and Accountability Act of 1996; therefore, no institutional review board review was required. For all other analyses, only aggregate populationbased data were used; patient-level data were not used in this study.

\section{EXCESS ECONOMIC BURDEN OF ADHD IN ADULTS}

Excess costs incurred by adults with ADHD in the United States in 2018 (the most recent calendar year for which claims data were available) were evaluated from a societal perspective; per-patient costs were extrapolated to the national level by using a prevalence-based approach. Cost estimates were weighted on the basis of the distribution of characteristics (eg, prevalence of ADHD by sex from published studies that stratified their populations by male and female) among the US population in 2018. Multiple data sources were leveraged in order to estimate the average cost difference between adults with and adults without ADHD (Table 1). In the absence of individuals without ADHD, estimates were used from the general US population. Because some literature-derived parameters were collected before 2018, costs were inflated by using the Consumer Price Index, and population growth was accounted for by using the growth factor relative to 2018, which was derived from population estimates. ${ }^{23}$ Finally, cost components were defined so as to be mutually exclusive, nonoverlapping components in order to avoid double-counting costs. For example, costs associated with road traffic accidents did not include those for medical services to treat injuries, which may have led to underestimation of this cost component.

A sensitivity analysis was also conducted by varying the prevalence, excess total direct health care costs of uninsured patients, the discount rate, and the proportion of adults with ADHD who seek treatment.

Direct Health Care Costs. Direct health care costs for insured patients (Medicaid- and commercially insured patients) were assessed from the payer's (ie, paid amount) and beneficiary's (ie, out-of-pocket costs) perspective. Patients with ADHD (those who had at least 2 diagnoses of ADHD [ICD-9-CM code 314.0x; ICD-10-CM code F90.x] on distinct dates) were matched exactly to patients without ADHD (up to a 1:3 ratio) on the basis of characteristics including age, 


\section{TABLE 1 Summary of Clinical Findings and Costs for Each Component of the Total Economic Burden of ADHD}

\begin{tabular}{|c|c|c|c|c|c|c|}
\hline & $\begin{array}{l}\text { Excess due } \\
\text { to ADHD }\end{array}$ & $\begin{array}{c}\text { No. of } \\
\text { individuals }\end{array}$ & Unit cost & $\begin{array}{c}\text { Excess costs due } \\
\text { to ADHD }\end{array}$ & $\begin{array}{l}\text { Excess costs } \\
\text { per individual }\end{array}$ & Reference \\
\hline Direct health care costs & $\$ 3,791^{a}$ & $3,774,449$ & - & $\$ 14,309,351,927$ & $\$ 1,642$ & MarketScan, 24 \\
\hline Direct non-health care costs & & & & $\$ 3,104,454,279$ & $\$ 356$ & \\
\hline ADHD-related research and training & $\$ 38,189,311$ & - & - & $\$ 38,189,311$ & $\$ 4$ & 26 \\
\hline Substance use disorder & - & - & - & $\$ 487,246,153$ & $\$ 56$ & \\
\hline Alcohol use disorder & $3.7 \%$ & 319,136 & $\$ 624$ & $\$ 199,235,283^{b}$ & - & $3,65,66$ \\
\hline Drug use disorder & $1.0 \%$ & 91,182 & $\$ 3,159$ & $\$ 288,010,870^{b}$ & - & $3,66,67$ \\
\hline Road traffic accidents & $\begin{array}{l}1.23 \text { times the } \\
\text { accident rate }\end{array}$ & 52,364 more & $\begin{array}{c}\$ 39,539 \text { per } \\
\text { accident }\end{array}$ & $\$ 2,070,426,868^{c}$ & $\$ 238$ & $9,68,69$ \\
\hline Disability & - & 52,915 & $\$ 9,612$ & $\$ 508,591,946^{d}$ & $\$ 58$ & 25 \\
\hline Indirect costs & & & & $\$ 105,424,004,458$ & $\$ 12,094$ & \\
\hline Unemployment & - & - & - & $\$ 66,777,318,174$ & $\$ 7,661$ & $29,70,71$ \\
\hline Men & $22.1 \%$ & $1,182,906$ & $\$ 47,173$ & $\$ 55,801,227,071^{\mathrm{e}}$ & - & \\
\hline Women & $9.7 \%$ & 324,420 & $\$ 33,833$ & $\$ 10,976,091,104^{e}$ & - & \\
\hline Productivity loss at work & & & & $\$ 28,754,104,472$ & $\$ 3,299$ & 30,71 \\
\hline Men & - & - & - & $\$ 19,836,561,783$ & - & \\
\hline Absenteeism & 13.6 days/year & $3,106,015$ & $\$ 181$ & $\$ 7,664,126,143^{f}$ & - & \\
\hline Presenteeism & 21.6 days/year & $3,106,015$ & $\$ 181$ & $\$ 12,172,435,640^{f}$ & - & \\
\hline Women & - & - & - & $\$ 8,917,542,689$ & - & \\
\hline Absenteeism & 13.6 days/year & $1,946,863$ & $\$ 130$ & $\$ 3,445,414,221^{\dagger}$ & - & \\
\hline Presenteeism & 21.6 days/year & $1,946,863$ & $\$ 130$ & $\$ 5,472,128,468^{f}$ & - & \\
\hline Caregiving & 41 hours/year & $8,716,972$ & $\$ 19$ & $\$ 6,648,915,195^{g}$ & $\$ 763$ & $31,32,72,73$ \\
\hline Premature mortality & $\begin{array}{l}1.5 \text { times the } \\
\text { mortality rate }\end{array}$ & 16,419 & $\$ 15,181-\$ 51,014$ & $\$ 3,243,666,617^{h}$ & $\$ 372$ & $12,70,74$ \\
\hline
\end{tabular}

Note: Data are for adults aged 18-65 years. All costs are presented as US dollars.

${ }^{a}$ Details regarding the calculation of excess direct health care costs are described in Figure 3.

${ }^{b}$ Calculated as the excess number of adults with alcohol or drug abuse disorder due to ADHD multiplied by the average cost of an adult with alcohol or drug abuse disorder in the United States.

'Calculated as the excess number of road traffic accidents due to ADHD multiplied by the average cost of a road traffic accident in the United States.

${ }^{\mathrm{d} C a l c u l a t e d}$ as the excess number of adults with ADHD who receive disability benefits multiplied by the average annual disability benefit of adults with ADHD in the United States.

${ }^{e}$ Calculated as the excess number of unemployed male or female adults with ADHD multiplied by the median annual earnings of male or female employees in the United States.

${ }^{\prime}$ Calculated as the excess number of days per year lost due to ADHD-related absenteeism or presenteeism, multiplied by the median daily earnings of male or female employees, multiplied by the number of employed male or female adults with ADHD in the United States.

${ }^{9}$ Calculated as the number of adults with ADHD multiplied by the estimated annual cost of ADHD-related caregiving per adults with ADHD (ie, excess number of hours per year devoted to ADHD-related caregiving per individual with ADHD multiplied by the median hourly earnings of adults) in the United States.

${ }^{h}$ Calculated on the basis of the number of excess all-cause deaths among adults with ADHD, average annual earnings, the employment-to-population ratio per age group, and a $3.0 \%$ discount rate to estimate the excess productivity loss from all-cause deaths.

$A D H D=$ attention-deficit/hyperactivity disorder.

sex, region of residence (except for the Medicaid sample, for which this information was not available), race (except for the commercial sample, for which this information was not available), health plan, and the year of the index date (ie, the most recent calendar date followed by 12 months of continuous health plan coverage). Both all-cause pharmacy and medical costs were compared between the 2 cohorts; medical costs were broken down further into outpatient, inpatient, emergency room, and durable medical equipment costs. Because some patients with ADHD do not use 


\section{FIGURE 1 Excess Economic Burden of ADHD (US\$, Billions) Among the US Adult Population in 2018}

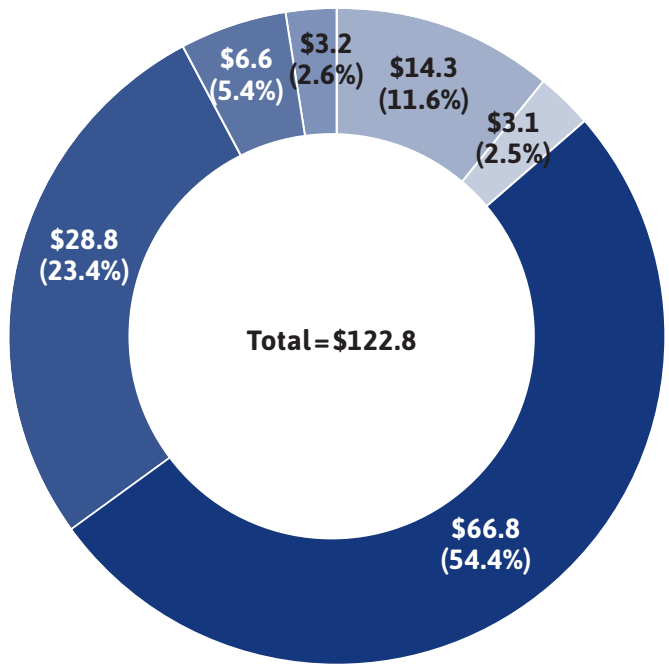

Excess direct health care costs

Excess direct non-health care costs

Excess costs of unemployment

Excess costs of productivity

Excess costs due to caregiving

Excess costs of premature mortality

$A D H D=$ attention-deficit/hyperactivity disorder .

health care services, excess direct health care costs were multiplied by the proportion of patients with ADHD who do receive health care services (43.3\%). ${ }^{3}$

The health care costs of uninsured individuals are partially covered by federal, state, and local institutions, and by the private sector. This total excess uncompensated cost was calculated by using both a prior estimate in the literature for the overall US population ${ }^{24}$ and the ratio of the total medical service costs incurred by Medicaid-insured patients with ADHD compared with that incurred by patients without ADHD, in order to account for the higher excess costs of uninsured individuals with ADHD.

Direct Non-Health Care Costs. Direct non-health care costs among adults with ADHD included those associated with research and training (ie, funding allocated for ADHD by the National Institutes of Health), comorbid SUD (ie, criminal justice system, property damage, crimerelated productivity loss, prevention and research), road traffic accidents (ie, property damage, congestion, legal, workplace, insurance, household productivity, market productivity), and disability (ie, Social Security Administration disability benefits). Excess direct non-health care costs associated with ADHD in adults were derived from the existing peer-reviewed literature and other governmental publications. ${ }^{3,9,25,26}$ These government publications were based on nationally representative government surveys, such as the National Comorbidity Survey, and other government data and publications. The National Comorbidity Survey is a nationally representative community household survey of the prevalence and correlates of mental disorders in the United States., ${ }^{3,27}$

Indirect Costs. The indirect excess costs associated with ADHD in adults were calculated by using the existing literature and governmental sources. A human capital approach, whereby costs were derived from paid work compensation rates,$^{28}$ was used in order to estimate these costs (ie, individual time was valued at the expected income level). Cost components included in this category were unemployment, productivity (ie, presenteeism and absenteeism), mortality, and caregiving costs (eg, help getting to and from medical appointments, reminders to take medication).

\section{Results}

According to one of the most recent prevalence estimates for ADHD among adults (4.4\%), ${ }^{3}$ an estimated $8,716,972$ adults were living with ADHD in the United States in 2018. The total societal excess cost attributable to ADHD in 2018 was $\$ 122.8$ billion, or $\$ 14,092$ per adult (Figures 1 and 2A). The sensitivity analysis showed that total excess cost ranges from $\$ 70.9$ billion to $\$ 124.9$ billion. Figure 1 illustrates the total excess cost attributable to ADHD in adults and component costs attributable to direct health care, direct non-health care, and indirect costs.

\section{DIRECT HEALTH CARE COSTS}

The excess direct health care costs associated with ADHD among adults in 2018 was estimated at $\$ 3,791$ per individual. Specifically, ADHD is associated with annual excess direct health care costs of $\$ 3,760$ per adult with commercial insurance, $\$ 4,897$ per adult with Medicaid insurance, and \$2,754 per uninsured adult (Figure 3). Given that only $43.3 \%$ of adults with ADHD are estimated to receive any health care services (not necessarily ADHD-specific treatments), ${ }^{3}$ the resulting excess direct health care cost was $\$ 14.3$ billion in 2018 (Figure 1). 


\section{DIRECT NON-HEALTH CARE COSTS}

ADHD-Related Research and Training. In 2018, the National Institutes of Health awarded $\$ 58.0$ million in funding for ADHD-related research and training. ${ }^{26}$ Assuming that the funding allocated to research on adults with ADHD is proportional to their share of the overall ADHD population, total excess ADHD-related research and training costs in 2018 are estimated at $\$ 38.2$ million (Table 1).

Substance Use Disorder. Approximately 5.9\% of adults with ADHD and 2.2\% of adults without ADHD experience alcohol abuse. ${ }^{3}$ Similarly, $2.4 \%$ of adults with ADHD and $1.4 \%$ of those without ADHD experience drug abuse. ${ }^{3}$ The resulting annual excess cost associated with SUD is \$487 million, which includes costs associated with the criminal justice system, crime victims (property and damage), crime-related loss of productivity, and prevention and research (Table 1).

Road Traffic Accidents. Drivers with ADHD have a 23\% higher risk of road traffic accidents than do drivers without ADHD. ${ }^{9}$ This incremental risk translates into 52,364 additional road traffic accidents annually, resulting in excess costs estimated at $\$ 2.1$ billion (Table 1 ).

Disability. An estimated 52,915 adults claimed social security benefits, supplemental security income disability benefits, or both for ADHD in 2018, ${ }^{25}$ which translates into annual excess costs of $\$ 508.6$ million (Figure 1).

\section{INDIRECT COSTS}

Unemployment. Adult men with ADHD are 2.1 times more likely than adult men without ADHD to be unemployed, ${ }^{29}$ which equates to an excess unemployment rate of 22.1 percentage points versus comparable men without ADHD. Women with ADHD have a 1.3 times higher risk of unemployment than do women without $\mathrm{ADHD},{ }^{29}$ resulting in an excess unemployment rate of 9.7 percentage points. The annual excess cost due to unemployment is estimated at \$66.8 billion: $\$ 55.8$ billion for adult men and \$11.0 billion for adult women (Table 1).

Productivity Loss at Work. Overall, 13.6 and 21.6 work days are lost per year because of ADHD-related absenteeism and ADHD-related presenteeism, respectively. ${ }^{30}$ Taking into account differing daily earnings and employment rates between adult men and women in the United States, excess productivity costs due to ADHD are estimated at \$19.9 billion among men and $\$ 8.9$ billion among women, yielding \$28.8 billion in excess annual costs (Figure 1 and Table 1).

Caregiving. On average, caregivers of adults with ADHD spend an additional 0.8 hours/week providing ADHDrelated care that adults in the US general population do not spend. ${ }^{31,32}$ This incremental caregiver burden translates to estimated annual excess costs of $\$ 6.6$ billion (Figure 1 and Table 1).

Premature Mortality. ADHD among adults is associated with an approximately $50 \%$ higher annual rate of mortality, which is driven mainly by a higher rate of accidents (eg, road traffic accidents). ${ }^{12}$ This incremental risk of early death resulted in a total of approximately $\$ 3.2$ billion in societal productivity lost because of ADHD in 2018 (Figure 1 and Table 1).

\section{Discussion}

This study demonstrates the substantial economic burden associated with ADHD among adults in the United States. After accounting for a wide range of detrimental outcomes relevant to ADHD, the overall excess cost of ADHD among adults in 2018 was estimated at $\$ 122.8$ billion, or $\$ 14,092$ per adult. Although the excess economic burden of ADHD is comparable to that of several other medical conditions (Figure 2B), one of the important findings of our study is that most of the excess cost is driven by indirect costs, specifically unemployment and productivity loss, as opposed to direct costs. Unemployment and productivity loss accounted for nearly $\$ 96$ billion of the annual excess cost. This amount is in line with findings from a systematic literature review by Doshi et al, ${ }^{14}$ who found that productivity and income losses ( $\$ 87$ billion to $\$ 138$ billion) accounted for the largest proportion of the total excess annual burden ( $\$ 105$ billion to \$194 billion) associated with ADHD in adults. On the other hand, direct health care costs such as hospitalization, emergency department visits, and office visits also contributed to the total excess cost of ADHD in adults found in this study, but to a lesser extent at $11.6 \%$, or $\$ 14.3$ billion. Together with the literature, the current results establish ADHD as a costly disorder and point to several unmet medical needs among the adult population.

First, it is useful to compare the excess economic burden of ADHD identified in this study with that of other diseases in order to appraise its relative magnitude. This body of evidence suggests that ADHD among adults is associated with a per-patient economic burden comparable to that of depression and higher than that of anxiety (Figure 2A). ${ }^{33,34}$ Figure 2B compares the total excess economic burden of ADHD with that of other medical conditions in adults. Figure 2 illustrates that ADHD in adults is a costly condition. Given that the indirect costs drove much of the excess cost burden, employers and government agencies supporting unemployment benefits are key stakeholders and should be especially interested in ways to better manage ADHD in adults and to reduce these costs. 


\section{FIGURE 2 Excess Economic Burden of ADHD and Other Mental and Chronic Health Conditions, Per Individual (A) and in Total (B), Among the Adult US Population in 2018}

\section{A. Per individual excess cost}

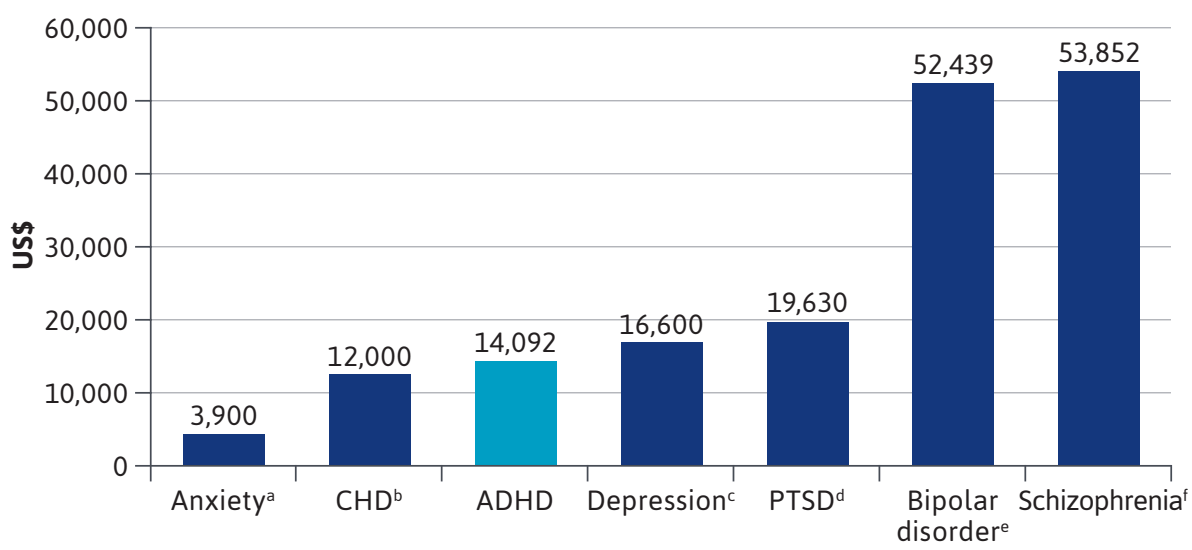

\section{B. Total excess cost}

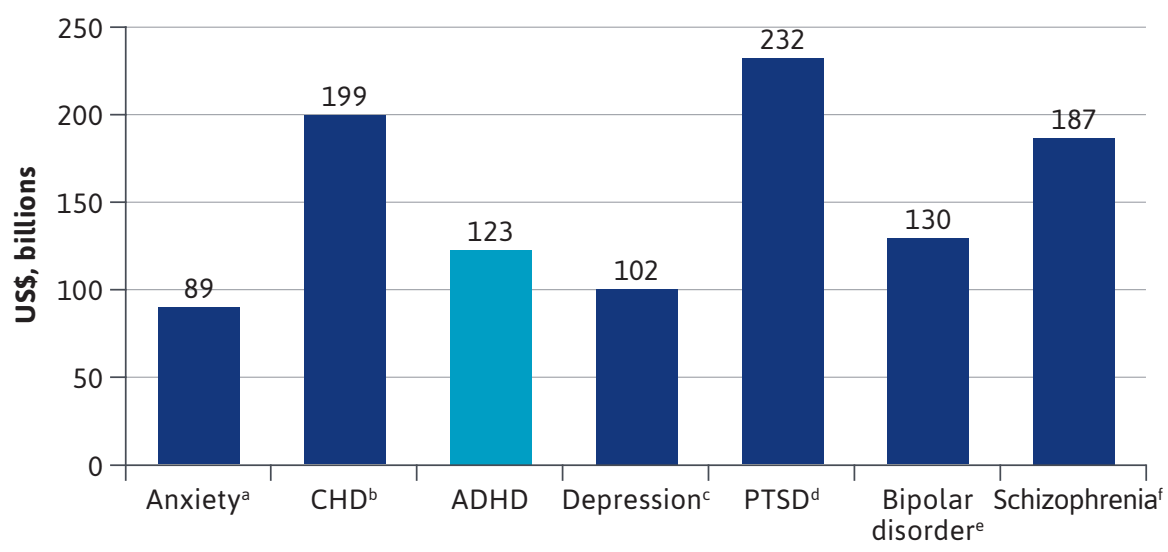

Note: The methods, populations, and components used in the cited studies from which these data were taken may differ, and results may not be fully comparable. Cost estimates are presented in 2018 US dollars and were adjusted by using the Bureau of Labor Statistics Consumer Price Index inflation factor, where applicable.

${ }^{a}$ Costs for anxiety include direct costs of health care, indirect costs of morbidity and mortality, and other costs of crime, social welfare, incarceration, and caregiving. ${ }^{75}$

${ }^{b}$ Costs for CHD include direct costs of health care and indirect costs of unemployment, productivity loss, and premature mortality. ${ }^{76}$

'Costs for depression include direct costs of health care and indirect costs of depression-related morbidity in the workplace and premature mortality due to depression-related suicides. ${ }^{34}$

${ }^{d}$ Costs for PTSD include direct costs of health care, research and training, substance use disorder, psychotherapy services not covered under health plans, homelessness, and disability, and indirect costs of unemployment, productivity loss, caregiving, and premature mortality. ${ }^{77}$

eCosts of bipolar disorder, considered to be a severe mental illness, include direct costs of health care, research and training, and substance abuse, and indirect costs of unemployment, productivity loss, caregiving, direct health care costs of caregivers, and premature mortality. ${ }^{78}$

'Costs of schizophrenia, considered to be a severe mental illness, include direct costs of health care, research and training, homelessness, and law enforcement, and indirect costs of unemployment productivity loss, caregiving, and premature mortality due to suicide. ${ }^{79}$

$A D H D=$ attention-deficit/hyperactivity disorder; $C H D=$ coronary heart disease; $P T S D=$ posttraumatic stress disorder.
One area of unmet need that may contribute to the large burden of ADHD is that the condition is commonly undiagnosed in adults, thus leaving symptoms untreated, which points to insufficiencies at both the patient and physician levels. ${ }^{35,36}$ At the patient level, some adults may present with ADHD that was not diagnosed during childhood and thus may be more difficult to diagnose during adulthood because of changes in clinical presentation associated with age, such as adults' internalization of the typical hyperactivity symptoms. ${ }^{35-38}$ In addition, adults may develop better compensation strategies to further mask recognizable symptoms of ADHD. ${ }^{38}$ ADHD among adults may also be undiagnosed because it is instead misdiagnosed as another comorbid condition; ADHD symptoms are often mistaken for those of mood and anxiety disorders or personality disorders, among others. . $^{35,38}$

At the physician level, data suggest that health care providers may also benefit from increased knowledge of ADHD in adults. ${ }^{39,40}$ A recent survey of psychiatrists, primary care physicians, neurologists, and nurse practitioners found that a substantial proportion of respondents (particularly nonpsychiatrists) exhibited limited confidence in their ability to diagnose ADHD in adults. ${ }^{39}$ Furthermore, approximately $40 \%-70 \%$ of physicians across specialties only occasionally or rarely/ never screen or test for ADHD among adults with depression/anxiety, which may contribute to underdiagnosis. ${ }^{39}$ This diagnostic uncertainty of ADHD in adults may be a result of the traditional perception of ADHD as a childhood condition, thus decreasing its perceived relevance as a serious diagnosis in adults who present with symptoms. ${ }^{39}$ Taken together, the complexity of associating, at both the patient and the physician level, ADHD symptoms with a diagnosis of ADHD 


\section{FIGURE 3 Annual Direct Health Care Costs Among Adults With ADHD and Those Without ADHD}

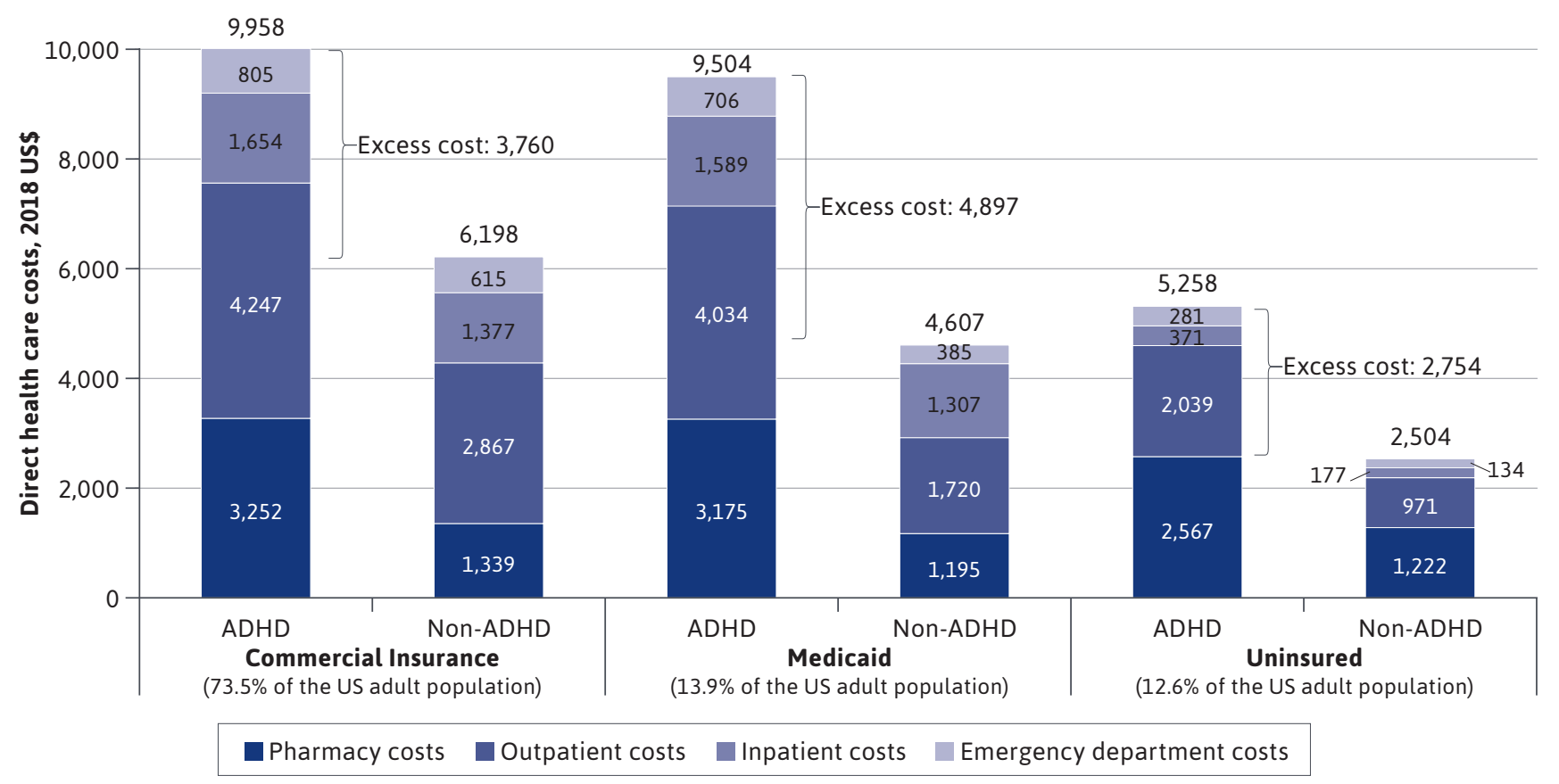

$A D H D=$ attention-deficit/hyperactivity disorder .

in the context of other coexisting conditions may prevent adult patients with ADHD from receiving appropriate interventions, which may exacerbate their symptoms and, by extension, contribute to the considerable societal burden identified in this study. Better utilization of existing screening tools may help to address the underdiagnosis of ADHD in adults.

In addition to underdiagnosis of ADHD, undertreatment of ADHD in adults is another issue. Even among adults who are correctly diagnosed with ADHD, the National Comorbidity Survey Replication (2001-2003) estimated that approximately $89 \%$ did not receive treatment for their condition, despite experiencing significant role impairment due to ADHD.,27 Lack of treatment has been associated with deleterious outcomes. For instance, untreated individuals with ADHD have a higher risk of road traffic accidents, achieve poorer academic performance, and demonstrate impaired social function relative to treated individuals. ${ }^{8,41-44}$ The presence of comorbidities may represent an important barrier to receiving ADHD-specific treatment. ${ }^{3}$ Indeed, many patients receive therapy for comorbid mental or behavioral problems instead of $\mathrm{ADHD}, 3,45$ as an extensive comorbidity profile further complicates treatment. ${ }^{1,46,47}$ This mistreatment becomes a self-perpetuating problem because a lack of ADHD treatment is further associated with an increased risk of developing comorbidities, including depression and SUD. ${ }^{48-50}$ Given the substantial excess costs incurred by adults with ADHD as identified in this study-including costs associated with road traffic accidents and SUD (both of which have been shown to be exacerbated among those whose ADHD is untreated)-increasing the proportion of patients who receive ADHD-related therapy may help address this high burden by reducing the risk of developing these costly comorbidities and harmful effects.

Although most adults with ADHD remain untreated, ${ }^{3}$ strategies are needed to help those patients who are receiving treatment persist with or adhere to treatment. Current pharmacologic therapies are often associated with poor adherence, frequent medication switching, and early discontinuation..$^{51-53}$ For instance, a systematic literature review reported that during a 12-month period patients took their medication, on average, half of the time and stopped treatment after 6-8 months. ${ }^{52}$ Reasons for nonadherence and treatment discontinuation vary and are not well understood in adults; lack of efficacy (or durability of efficacy), adverse effects (eg, sleep difficulties, gastrointestinal disturbances, 
dry mouth), social stigma, dosing inconvenience, and other reasons (eg, barriers to accessing stimulant medications as controlled substances) may contribute to the explanation. ${ }^{54-57}$ Nonpharmacologic therapy such as cognitive behavioral therapy and psychoeducation can be used as a complement to pharmacologic therapy, ${ }^{58,59}$ but its documented benefits are more limited. ${ }^{60}$ As such, even among the small proportion of adults in whom ADHD is diagnosed and who receive treatment, there is an unmet need for improved treatment adherence, potentially supported by more efficacious and tolerable treatments, which may help to alleviate the burden of ADHD.

This suboptimal diagnosis and treatment may stem from a lack of awareness of ADHD in adults among patients and physicians. Indeed, no treatment guidelines for adults with ADHD are available in the United States, aside from a preliminary set of quality measures that may eventually be used to develop guidelines. ${ }^{61}$ Altogether, this emphasizes the urgent need for additional resources to better support this undertreated population. Accordingly, additional education and information programs to increase visibility around ADHD among the medical community may be of particular benefit for physicians to facilitate the identification, diagnosis, and treatment of this condition. ${ }^{36,39}$ With other mental illnesses such as SUD and posttraumatic stress disorder, intervention programs have been successfully introduced to raise awareness, reduce social stigma around seeking support, and help reintegrate individuals into employment settings. ${ }^{62-64}$ Similar efforts may be helpful to address the current underrecognition of ADHD in adults. Ultimately, greater societal acknowledgement may be key to improving diagnostic accuracy in, proper interventions for, and outcomes of adults with ADHD, which may help to reduce the substantial societal costs associated with this condition.

\section{LIMITATIONS}

This study is subject to some limitations. First, ADHD is underdiagnosed among adults, so the excess costs reported in this study may not fully capture the economic burden of this condition. Indeed, direct health care costs were obtained by using codes from claims for diagnosed adults (aged 18-64 years) who have either commercial insurance, Medicaid, or no insurance; therefore, the cost estimates may not be generalizable to older patients covered under Medicare. Although cost components were calculated by considering the undiagnosed and untreated population with ADHD whenever possible, these estimates were based on the available literature, which may not have always included this population; therefore, the costs reported in this study may be somewhat underestimated. On the contrary, ADHD may have also been overdiagnosed in the studies included in this analysis.

A second limitation is that excess direct non-health care costs and indirect costs were estimated by using values derived from the literature. Thus the quality of the assessment of individual cost components was contingent on the availability and accuracy of these data. Third, component costs may have been underestimated if one component was partially covered by another, as each component was calculated to be mutually exclusive in order to avoid double-counting costs. Fourth, for certain components, excess costs could not be calculated by using individuals without ADHD as matched controls because of the unavailability of published data; the general US population was used instead as a comparator for these components. Finally, this study integrated values that had been derived from heterogeneous patient populations and analyzed through various study designs and methods.

\section{Conclusions}

This comprehensive evaluation of societal costs estimated the total excess costs for adults with ADHD at $\$ 122.8$ billion in the United States in 2018. These results suggest that ADHD in adults and its associated costs, which are already important to patients and family members, must also be recognized by providers and payers. Another key group affected by ADHD in adults is employers. Indeed, unemployment and productivity loss accounted for nearly $80 \%$ of this excess cost, showing that the scope of the burden of ADHD among adults extends far beyond direct health care costs. Improving awareness and, as a consequence, proper management and treatment of ADHD in adults may prove instrumental in reducing the high economic burden associated with this condition.

\section{DISCLOSURES}

This study was funded by Otsuka Pharmaceutical Development \& Commercialization, Inc. (Otsuka). The study sponsor contributed to and approved the study design, participated in the interpretation of data, and reviewed and approved the manuscript. Schein is an employee of Otsuka. Gagnon-Sanschagrin, Davidson, Kinkead, Cloutier, Guérin, and Lefebvre are employees of Analysis Group, Inc., a consulting company that provided paid consulting services to Otsuka to develop and conduct this study and write the manuscript.

Adler has received research support from Shire/Takeda, Sunovion, and Otsuka; consulting fees from Bracket, Shire/ Takeda, Sunovion, Otsuka, the State University of New York (SUNY), the National Football League (NFL), and Major League 
Baseball (MLB); and royalty payments (as inventor) from New York University (NYU) for license of adult ADHD scales and training materials. Childress has received research support from Allergan, Takeda/ Shire, Emalex, Akili, Ironshore, Arbor, Aevi Genomic Medicine, Neos Therapeutics, Otsuka, Pfizer, Purdue, Rhodes, Sunovion, Tris, KemPharm, Supernus, and the US Food and Drug Administration; was on the advisory board of Takeda/Shire, Akili, Arbor, Cingulate, Ironshore, Neos Therapeutics, Otsuka, Pfizer, Purdue, Adlon, Rhodes, Sunovion, Tris, Supernus, and Corium; received consulting fees from Arbor, Ironshore, Neos Therapeutics, Purdue, Rhodes, Sunovion, Tris, KemPharm, Supernus, Corium, Jazz, and Tulex Pharma; received speaker fees from Takeda/Shire, Arbor, Ironshore, Neos Therapeutics, Pfizer, Tris, and Supernus; and received writing support from Takeda/Shire, Arbor, Ironshore, Neos Therapeutics, Pfizer, Purdue, Rhodes, Sunovion, and Tris.

Part of the material in this study was presented as a poster at the International Society for Pharmacoeconomics and Outcomes Research (ISPOR) 2021 Virtual Meeting; May 17-20, 2021.

\section{ACKNOWLEDGMENTS}

Medical writing assistance was provided by Christine Tam, an employee of Analysis Group, Inc.

\section{REFERENCES}

1. Faraone SV, Asherson P, Banaschewski T, et al. Attention-deficit/hyperactivity disorder. Nat Rev Dis Primers. 2015;1:15020.

2. Posner J, Polanczyk GV, Sonuga-Barke E. Attention-deficit hyperactivity disorder. Lancet. 2020;395(10222):450-62.

3. Kessler RC, Adler L, Barkley R, et al. The prevalence and correlates of adult ADHD in the United States: results from the National Comorbidity Survey Replication. Am J Psychiatry. 2006;163(4):716-23.

4. Biederman J, Petty CR, Evans M, Small J, Faraone SV. How persistent is ADHD? A controlled 10-year follow-up study of boys with ADHD. Psychiatry Res. 2010;177(3):299-304.
5. Kessler RC, Adler LA, Barkley R, et al. Patterns and predictors of attentiondeficit/hyperactivity disorder persistence into adulthood: results from the National Comorbidity Survey Replication. Biol Psychiatry. 2005;57(11):1442-51.

6. Biederman J, Monuteaux MC, Mick E, et al. Young adult outcome of attention deficit hyperactivity disorder: a controlled 10-year follow-up study. Psychol Med. 2006;36(2):167-79.

7. Klein RG, Mannuzza S, Olazagasti MA, et al. Clinical and functional outcome of childhood attention-deficit/hyperactivity disorder 33 years later. Arch Gen Psychiatry. 2012;69(12):1295-303.

8. Chang Z, Lichtenstein P, D’Onofrio BM, Sjolander A, Larsson H. Serious transport accidents in adults with attention-deficit/ hyperactivity disorder and the effect of medication: a population-based study. JAMA Psychiatry. 2014;71(3):319-25.

9. Vaa T. ADHD and relative risk of accidents in road traffic: a meta-analysis. Accid Anal Prev. 2014;62:415-25.

10. Charach A, Yeung E, Climans T, Lillie E. Childhood attention-deficit/hyperactivity disorder and future substance use disorders: comparative meta-analyses. J Am Acad Child Adolesc Psychiatry. 2011;50(1):9-21.

11. Biederman J, Faraone SV, Spencer T, et al. Patterns of psychiatric comorbidity, cognition, and psychosocial functioning in adults with attention deficit hyperactivity disorder. Am J Psychiatry. 1993;150(12):1792-98.

12. Dalsgaard S, Ostergaard SD, Leckman JF, Mortensen PB, Pedersen MG. Mortality in children, adolescents, and adults with attention deficit hyperactivity disorder: a nationwide cohort study. Lancet. 2015;385(9983):2190-96.

13. Birnbaum HG, Kessler RC, Lowe SW, et al. Costs of attention deficit-hyperactivity disorder (ADHD) in the US: excess costs of persons with ADHD and their family members in 2000. Curr Med Res Opin. 2005;21(2):195-206.
14. Doshi JA, Hodgkins P, Kahle J, et al. Economic impact of childhood and adult attention-deficit/hyperactivity disorder in the United States. J Am Acad Child Adolesc Psychiatry. 2012;51(10):990-1002.e2.

15. Gupte-Singh K, Singh RR, Lawson KA. Economic burden of attention-deficit/ hyperactivity disorder among pediatric patients in the United States. Value Health. 2017;20(4):602-9.

16. Hodgkins P, Montejano L, Sasané R, Huse D. Cost of illness and comorbidities in adults diagnosed with attention-deficit/hyperactivity disorder: a retrospective analysis. Prim Care Companion CNS Disord. 2011;13(2):PCC.10m01030.

17. Kleinman NL, Durkin M, Melkonian A, Markosyan K. Incremental employee health benefit costs, absence days, and turnover among employees with ADHD and among employees with children with ADHD. J Occup Environ Med. 2009;51(11):1247-55.

18. Leibson CL, Katusic SK, Barbaresi WJ, Ransom J, O'Brien PC. Use and costs of medical care for children and adolescents with and without attentiondeficit/hyperactivity disorder. JAMA. 2001;285(1):60-66.

19. Meyers J, Classi P, Wietecha L, Candrilli S. Economic burden and comorbidities of attention-deficit/hyperactivity disorder among pediatric patients hospitalized in the United States. Child Adolesc Psychiatry Ment Health. 2010;4:31.

20. Molife C, Haynes VS, Nyhuis A, et al. Healthcare utilization and costs of children with attention deficit/hyperactivity disorder initiating atomoxetine versus extended-release guanfacine. Curr Med Res Opin. 2018;34(4):619-32.

21. Ray GT, Levine P, Croen LA, Bokhari FA, Hu TW, Habel LA. Attention-deficit/ hyperactivity disorder in children: excess costs before and after initial diagnosis and treatment cost differences by ethnicity. Arch Pediatr Adolesc Med. 2006;160(10):1063-69. 
22. Chhibber A, Watanabe AH, Chaisai C, Veettil SK, Chaiyakunapruk N. Global economic burden of attention-deficit/ hyperactivity disorder: a systematic review. Pharmacoeconomics. 2021;39(4):399-420.

23. Kaiser Family Foundation. Health insurance coverage of the total population. 2019. Accessed September 22, 2021. https://www.kff.org/other/state-indicator/total-population/?currentTimeframe =0\&sortModel=\%7B\%22colId\%22:\%22Loca tion\%22,\%22sort\%22:\%22asc\%22\%7D

24. Agency for Healthcare Research and Quality. Mean expenditure per person with expense by insurance coverage, United States, 2017. Medical Expenditure Panel Survey. Generated interactively. May 13 2020. https://meps.ahrq.gov/ mepstrends/hc_use/

25. Social Security Administration. Master Beneficiary Record and Supplemental Security Record, 100 percent data. Distribution of beneficiaries aged 18-64, by diagnostic group, December 2018. Accessed March 3, 2020. https://www. ssa.gov/policy/docs/statcomps/di_ asr/2018/sect05.html

26. US Department of Health and Human Services. Estimates of funding for various research, condition, and disease categories (RCDC). 2019. Accessed October 3, 2019. https://report.nih.gov/categorical_spending.aspx

27. Kessler RC, Berglund P, Chiu WT, et al. The US National Comorbidity Survey Replication (NCS-R): design and field procedures. Int J Methods Psychiatr Res. 2004;13(2):69-92.

28. Robinson R. Cost-benefit analysis. BMJ. 1993;307(6909):924-26.

29. Biederman J, Faraone SV. The effects of attention-deficit/hyperactivity disorder on employment and household income. MedGenMed. 2006;8(3):12.

30. Kessler RC, Adler L, Ames M, et al. The prevalence and effects of adult attention deficit/hyperactivity disorder on work performance in a nationally representative sample of workers. J Occup Environ Med. 2005;47(6):565-72.
31. National Alliance for Caregiving (NAC). On pins and needles: caregivers of adults with mental illness. February 2016. Accessed February 18, 2020. https:// www.mhanational.org/sites/default/ files/2019-07/NAC_Mental_Illness_ Study 2016 FINAL WEB.pdf

32. National Alliance for Caregiving (NAC). Caregiving in the U.S.: 2015 report. June 2015. Accessed February 18, 2020. https://www.caregiving.org/ wp-content/uploads/2020/05/2015_ CaregivingintheUS_Final-Report-June-4_ WEB.pdf

33. Greenberg PE, Stiglin LE, Finkelstein SN, Berndt ER. The economic burden of depression in 1990. J Clin Psychiatry. 1993;54(11):405-18.

34. Greenberg PE, Sisitsky T, Kessler RC, et al. The economic burden of anxiety disorders in the 1990s. J Clin Psychiatry. 1999;60(7):427-35.

35. Ginsberg Y, Quintero J, Anand E, Casillas M, Upadhyaya HP. Underdiagnosis of attention-deficit/hyperactivity disorder in adult patients: a review of the literature. Prim Care Companion CNS Disord. 2014;16(3):PCC.13r01600.

36. Oliva F, Malandrone F, Mirabella S, Ferreri P, di Girolamo G, Maina G. Diagnostic delay in ADHD: duration of untreated illness and its socio-demographic and clinical predictors in a sample of adult outpatients. Early Interv Psychiatry. 2021;15(4):957-65.

37. Rao P, Place M. Prevalence of ADHD in four general adult outpatient clinics in North East England. Prog Neurol Psychiatry. 2011;15(5):7-10.

38. Weibel S, Menard O, Ionita A, et al. Practical considerations for the evaluation and management of attention deficit hyperactivity disorder (ADHD) in adults. Encephale. 2020;46(1):30-40.

39. Adler LA, Farahbakhshian S, Romero B, Flood E, Doll H. Healthcare provider perspectives on diagnosing and treating adults with attention-deficit/ hyperactivity disorder. Postgrad Med. 2019;131(7):461-72.
40. Goodman DW, Surman CB, Scherer PB, Salinas GD, Brown JJ. Assessment of physician practices in adult attentiondeficit/hyperactivity disorder. Prim Care Companion CNS Disord. 2012;14(4):PCC.11m01312.

41. Arnold LE, Hodgkins P, Kahle J, Madhoo M, Kewley G. Long-term outcomes of ADHD: academic achievement and performance. J Atten Disord. 2020;24(1):73-85.

42. Barbaresi WJ, Katusic SK, Colligan RC, Weaver AL, Jacobsen SJ. Modifiers of longterm school outcomes for children with attention-deficit/hyperactivity disorder: does treatment with stimulant medication make a difference? Results from a population-based study. J Dev Behav Pediatr. 2007;28(4):274-87.

43. Shaw M, Hodgkins P, Caci H, et al. A systematic review and analysis of long-term outcomes in attention deficit hyperactivity disorder: effects of treatment and non-treatment. BMC Med. 2012;10:99.

44. Surman CBH, Fried R, Rhodewalt L, Boland H. Do pharmaceuticals improve driving in individuals with ADHD? A review of the literature and evidence for clinical practice. CNS Drugs. 2017;31(10):857-66.

45. Fayyad J, Sampson NA, Hwang I, et al. The descriptive epidemiology of DSM-IV adult ADHD in the World Health Organization World Mental Health Surveys. Atten Defic Hyperact Disord. 2017;9(1):47-65.

46. Katzman MA, Bilkey TS, Chokka PR, Fallu A, Klassen LJ. Adult ADHD and comorbid disorders: clinical implications of a dimensional approach. BMC Psychiatry. 2017;17(1):302.

47. Post RE, Kurlansik SL. Diagnosis and management of adult attention-deficit/ hyperactivity disorder. Am Fam Physician. 2012;85(9):890-96.

48. Biederman J. Pharmacotherapy for attention-deficit/hyperactivity disorder (ADHD) decreases the risk for substance abuse: findings from a longitudinal followup of youths with and without ADHD. J Clin Psychiatry. 2003;64(Suppl 11):3-8. 
49. Chang Z, Lichtenstein P, Halldner L, et al. Stimulant ADHD medication and risk for substance abuse. J Child Psychol Psychiatry. 2014;55(8):878-85.

50. Lee MJ, Yang KC, Shyu YC, et al. Attention-deficit hyperactivity disorder, its treatment with medication and the probability of developing a depressive disorder: a nationwide populationbased study in Taiwan. J Affect Disord. 2016;189:110-17.

51. Adler LD, Nierenberg AA. Review of medication adherence in children and adults with ADHD. Postgrad Med. 2010;122(1):184-91.

52. Gajria K, Lu M, Sikirica V, et al. Adherence, persistence, and medication discontinuation in patients with attention-deficit/hyperactivity disorder - a systematic literature review. Neuropsychiatr Dis Treat. 2014;10:1543-69.

53. Olfson M, Marcus SC, Zhang HF, Wan GJ. Continuity in methylphenidate treatment of adults with attention-deficit/hyperactivity disorder. J Manag Care Pharm. 2007;13(7):570-77. doi:10.18553/ jmcp.2007.13.7.570

54. McGough JJ. Treatment controversies in Adult ADHD. Am J Psychiatry. 2016;173(10):960-66.

55. Frank E, Ozon C, Nair V, Othee K. Examining why patients with attention-deficit/hyperactivity disorder lack adherence to medication over the long term: a review and analysis. J Clin Psychiatry. 2015;76(11):e1459-68.

56. Kooij JJS, Bijlenga D, Salerno L, et al. Updated European Consensus Statement on diagnosis and treatment of adult ADHD. Eur Psychiatry. 2019;56:14-34.

57. Adler L, Dietrich A, Reimherr FW, et al. Safety and tolerability of once versus twice daily atomoxetine in adults with ADHD. Ann Clin Psychiatry. 2006;18(2):107-13.

58. Lopez PL, Torrente FM, Ciapponi A, et al. Cognitive-behavioural interventions for attention deficit hyperactivity disorder (ADHD) in adults. Cochrane Database Syst Rev. 2018;3(3):CD010840.
59. Vidal R, Bosch R, Nogueira M, et al. Psychoeducation for adults with attention deficit hyperactivity disorder vs. cognitive behavioral group therapy: a randomized controlled pilot study. J Nerv Ment Dis. 2013;201(10):894-900.

60. Sonuga-Barke EJ, Brandeis D, Cortese S, et al. Nonpharmacological interventions for ADHD: systematic review and meta-analyses of randomized controlled trials of dietary and psychological treatments. Am J Psychiatry. 2013;170(3):275-89.

61. Faraone SV, Silverstein MJ, Antshel K, et al. The Adult ADHD Quality Measures Initiative. J Atten Disord. 2019;23(10):1063-78.

62. Davis LL, Kyriakides TC, Suris AM, et al. Effect of evidence-based supported employment vs transitional work on achieving steady work among veterans with posttraumatic stress disorder: a randomized clinical trial. JAMA Psychiatry. 2018;75(4):316-24.

63. Heijnders M, Van Der Meij S. The fight against stigma: an overview of stigmareduction strategies and interventions. Psychol Health Med. 2006;11(3):353-63.

64. Livingston JD, Milne T, Fang ML, Amari E. The effectiveness of interventions for reducing stigma related to substance use disorders: a systematic review. Addiction. 2012;107(1):39-50.

65. Sacks JJ, Gonzales KR, Bouchery EE, Tomedi LE, Brewer RD. 2010 National and state costs of excessive alcohol consumption. Am J Prev Med. 2015;49(5):e73-79.

66. Substance Abuse and Mental Health Services Administration (SAMHSA). Results from the 2018 National Survey on Drug Use and Health: detailed tables. Center for Behavioral Health Statistics and Quality, National Survey on Drug Use and Health. 2019. Accessed December 16, 2019. https://www.samhsa.gov/data/

67. US Department of Justice National Drug Intelligence Center. The economic impact of illicit drug use on American society. 2011. Accessed December 18, 2019. https://www.justice.gov/archive/ndic/ pubs44/44731/44731p.pdf
68. National Highway Traffic Safety Administration. Police-reported motor vehicle crashes in 2018, Traffic Safety Facts. 2019. Accessed January, 15, 2020. https://crashstats.nhtsa.dot.gov/Api/ Public/Publication/812860\#: :text=In\%20 2018\%2C\%20there\%20were\%20an,fata lities\%20and\%202\%2C710\%2C000\%20 people\%20injured.

69. National Highway Traffic Safety Administration. The economic and societal impact of motor vehicle crashes, 2010 (revised). 2015. Accessed January 17, 2020. https://crashstats.nhtsa.dot.gov/Api/ Public/ViewPublication/812013

70. United States Census Bureau. Employment status 2018. 2018. Accessed February 11, 2020. https://data.census. gov/cedsci/table?q=unemployment\& hidePreview=true\&tid=ACSST1Y2018. $\underline{\text { S2301\&vintage }=2018}$.

71. United States Census Bureau. Work experience-people 15 years old and over, by total money earnings, age, race, hispanic origin, sex, and disability status. 2018. Accessed February 27, 2020. https:// www.census.gov/data/tables/timeseries/demo/income-poverty/cps-pinc/ pinc-05.html\#par textimage 0

72. United States Bureau of Labor Statistics. May 2018 national occupational employment and wage estimates United States. 2018. Accessed March 2, 2020. https://www.bls.gov/oes/2018/may/ oes nat.htm

73. National Alliance on Mental Illness. Mental health by the numbers. 2019. Accessed April 16, 2020. https://www. nami.org/mhstats

74. Kochanek KD, Murphy SL, Xu J, Arias E. Deaths: final data for 2017. 2019. Accessed October 14, 2019. https://stacks. cdc.gov/view/cdc/79486

75. DuPont RL, Rice DP, Miller LS, Shiraki SS, Rowland CR, Harwood HJ. Economic costs of anxiety disorders. Anxiety. 1996;2(4):167-72. 
76. American Heart Association. Cardiovascular disease: a costly burden for America projections through 2035. 2017. Accessed June 26, 2020. https://www.heart.org/idc/groups/ heart-public/@wcm/@adv/documents/ downloadable/ucm 491543.pdf
77. Davis LL, Schein J, Cloutier M, et al. The economic burden of post-traumatic stress disorder in the United States from a societal perspective. [abstract] J Manag Care Spec Pharm. 2021;27(4a):S61. Accessed November 16, 2021. doi:abs/10.18553/jmcp.2021.27.4-a.s1

78. Cloutier M, Greene M, Guérin A, Touya M, Wu E. The economic burden of bipolar I disorder in the United States in 2015. J Affect Disord. 2018;226:45-51.
79. Cloutier M, Sanon Aigbogun M, et al. The economic burden of schizophrenia in the United States in 2013. J Clin Psychiatry. 2016;77(6):764-71. 